\title{
Hipergeneralizações: organizações são quase qualquer coisa em best-sellers de introdução à Administração
}

\author{
Hyper-generalizations: organizations are almost anything in bestsellers of introduction to \\ Administration
}

Guilherme Lima Moura ${ }^{1}$

\begin{abstract}
Resumo
Este artigo almeja contribuir com reflexões sobre a qualidade da produção de sentido na Educação Superior em Administração no Brasil. Para tal, volta-se para uma análise semântica das definições de organização identificadas em pesquisa bibliográfica realizada nos livros-textos de introdução às teorias administrativas utilizados nas maiores e melhores instituições de Ensino Superior brasileiras. Esta análise definiu esses conceitos-chave como hipergeneralizações, em função de sua vagueza. Para aumentar sua precisão semântica, propõe-se a inclusão de historicidade e especificidade por meio da consideração do contexto que deu origem às organizações modernas. Essa simplificação conceitual generalizada produz efeitos éticos relevantes, ao descaracterizar dimensões da prática social coletiva no mundo das organizações. Afinal, o que se pode esperar de um campo que estuda "quase qualquer coisa"?
\end{abstract}

Palavras-chave: Ensino Superior em Administração no Brasil. Conceitos-chave. Semântica.

Abstract

This paper aims to contribute by means of reflections on the quality of meaning production in the Higher Education in Administration in Brazil. For this, it is aimed at a semantic analysis of the definitions of organization identified through a bibliographical survey conducted in textbooks introducing the administrative theories used in the biggest and best Brazilian Higher Education institutions. This analysis defined these key concepts as hyper-generalizations, due to their vagueness. For increasing their semantic accuracy, we propose the inclusion of historicity and specificity by considering the context that gave rise to modern organizations. This generalized conceptual simplification produces relevant ethical effects, by mischaracterizing dimensions of the collective social practice in the world of organizations. After all, what may we expect from a field that studies "almost anything"?

Keywords: High Education in Administration in Brazil. Key concepts. Semantics.

\footnotetext{
Artigo submetido em 19 de julho de 2013 e aceito para publicação em 29 de janeiro de 2014.

${ }^{1}$ Doutor em Linguística pela Universidade Federal de Pernambuco; Professor adjunto do Departamento de Ciências Administrativas da Universidade Federal de Pernambuco. Endereço: Av. dos Economistas, s/n, Cidade Universitária, CEP 50670-901, Recife - PE, Brasil. E-mail: glmoura@gmail.com
} 


\section{Apresentação}

Neste momento, estima-se quehajacerca de um milhão e meio de alunos matriculados em cursos de graduação em Administração por todo o Brasil. Segundo os dados do Censo da Educação Superior 2009 (INEP 2009; 2011; GUIA DO ESTUDANTE, 2011), atingimos naquela ocasião a impressionante marca de 1.102.579 alunos. Esse quantitativo representa quase o triplo de todo o alunado das engenharias, por exemplo. Estamos falando de 3.958 Instituições de Ensino Superior (IES) no ano de 2009 (contra 2.281 IES em 2007). ${ }^{2}$ De 1952 até 2008, pelo menos 1,5 milhão de pessoas receberam o diploma de administrador e a previsão é de que em 2013 cheguemos a mais de 2 milhões de formados. E os números não param de crescer: em 2007, ao mesmo tempo em que noventa mil estudantes formavam-se em Administração, outros 280 mil iniciavam-se como calouros nestes mesmos cursos.

Nenhum outro curso universitário no Brasil apresenta números nesse patamar. Segundo um levantamento do INEP realizado em 2006 (TAKAHASHI, 2009), havia naquele ano mais alunos universitários matriculados em Administração do que em toda a área de saúde (621 mil contra 549 mil alunos). Cursos como Física, Química e Agronomia, por exemplo, não chegaram a atingir naquele momento sequer o patamar de 35 mil alunos. $^{3}$

Mesmo com números desta magnitude, as perspectivas de mercado para os egressos são igualmente animadoras. Isso porque a estimativa atual é de que existam aproximadamente catorze milhões de administradores atuando formalmente no mercado de trabalho brasileiro, em mais de treze milhões de empresas. Esta especial combinação de números define a área de atuação profissional e o mercado de trabalho do administrador como de alta demanda e baixa competitividade (ANDRADE, 2009; CENSO/INEP, 2007 apud ANDRADE, 2009).

Para além dos números característicos desse impactante fenômeno sociocultural chamado "Graduação em Administraçãono Brasil", cabe a questão: o que temos feito, do ponto de vista da qualidade do ensino, com tais estudantes e futuros profissionais? Em busca de procurar respostas a esta pergunta, alguns valiosos estudos têm sido empreendidos nos últimos anos (FISCHER, 1984; 1993; NICOLINI, 2001; 2003;VERGARA e CARVALHO JR.; 1995; VERGARA e PINTO, 2000; 2001; MOURA, 2009; 2010; 2011).

O propósito deste artigo,em sentido amplo, é oferecer elementos que possam contribuir com estes esforços de reflexão sistemática sobre o sentido da educação superior em Administração. Em sentido estrito, ele se volta especificamente para uma análise semântica das definições de Organização, um dos principais conceitos-chave da área, identificados através de pesquisa bibliográfica realizada em livros-textos de introdução às teorias administrativas, usados nas maiores e melhores universidades brasileiras.

2 Takahashi (2009),Nicolini (2003, p. 47) e o Universia (2009) nos informam que, de acordo com dados do MEC, em 1967 tínhamos apenas 31 cursos; em 1973 saltamos para 177 cursos; nos anos 1980 chegamos a 245 cursos;em 1990 atingimos a marca de 330 cursos; em 1998 fomos para 549; em 2000 chegamos a 969; e em 2002 o MEC já identificava 1.395 IES com cursos de Administração espalhados por todas as 27 Unidades da Federação.

3 Segundo Nicolini (2003, p. 47), a proliferação dos cursos de graduação em Administração no Brasil nos últimos anos se deve em grande parte ao seu baixo custo de implantação que dispensa a existência de "laboratórios sofisticados e qualquer outro refinamento tecnológico", comparando-se, por exemplo, com a infra-estrutura necessária para o funcionamento dos cursos de Medicina. Outro curso que apresenta as mesmas facilidades de implantação é o de Direito, embora neste caso haja um processo de filtragem profissional realizado nos egressos pela OAB (segundo TAKAHASHI, 2009, o Conselho Federal de Administração também quer adotar um exame semelhante ao da OAB, sendo queo projeto já tramita no Congresso). Portanto, as amplas possibilidades de atuação no mercado profissional, associadas aos baixos custos de implantação dos cursos e à ausência de mecanismos oficiais de regulamentação da profissão, criariam as condições para este enorme contingente de alunos de graduação. 


\section{Management Industry e as Hipergeneralizações Best-Sellers em sala de aula}

As salas de aula daqueles cursos de graduação em Administração são também o lugar do fenômeno chamado Management Industry, que nomeia este número temático dos Cadernos EBAPE.BR, e que tem sido também rotulado de Management Fashion Setters ou Pop Management, entre outras expressões que assinalam a reprodução de determinados padrões conceituais concebidos como de natureza acrítica, volátil e superficial sobre os fenômenos administrativos (ABRAHAMSON, 1996; MICKLETHWAIT e WOOLDRIDGE, 1998; WOOD JR. e PAULA, 2006). É evidente que sua natureza discursiva é um significativo aspecto deste processo, que poderíamos aqui chamar de uma espécie de pasteurização semântica dos conceitos na área.

As disciplinas introdutórias dos cursos de Administração ${ }^{4}$ são geralmente o único momento de unidade didática e de iniciação sobre as organizações em todo o curso, após o qual este se desenrola fragmentadamente nas suas muitas disciplinas especialistas. Não haverá outra oportunidade na graduação, curricularmente prevista e estruturada, para o aluno pensar as organizações como um todo. É nessa breve leitura inicial que são ensinados os principais conceitos gerais da área. E para isso é tomada como referência básica determinada literatura de formação profissional.

A Management Industry neste artigo é, então, observada nessas salas de aula especificamente no que diz respeito ao que tem sido tratado como fragilidades semânticas das definições presentes nos manuais de introdução às teorias administrativas, usados por diversos cursos de graduação em Administração existentes no Brasil. A nossa prática docente inspirou um estudo mais específico, voltado à análise do conceito de Organização, que geralmente é traduzido naqueles livros como "qualquer atividade coletiva deliberada".

Boa parte desta fragilidade conceitual reside numa tendência de muitos autores a descontextualizar historicamente o fenômeno organização, propondo definições que podem se aplicar a praticamente qualquer atividade humana coletiva. Nada nos impede, então, de associar aqueles conceitos a fenômenos ou situações tão distintos e inusitados quanto, por exemplo: dois amigos jogando uma partida de tênis; um casal assistindo à tevê no domingo; uma quadrilha de assaltantes a caminho de um banco para assaltá-lo; um grupo de crianças brincado de esconde-esconde; um casal de namorados que decide casar-se; ou "até mesmo" o diretor de uma indústria em reunião com sua equipe de gerentes.

É importante notar que estas fragilidades conceituais aqui problematizadas não são meras inconsistências de natureza teórica ou semântica. Ou seja, não se trata: 1) de uma espécie de contradição ou "desamarração" argumentativa identificada em certos conceitosapresentados pelos livros didáticos; ou 2) de uma dificuldade exclusivamente semântica presente em algumas expressões conceituais, pela sua ambiguidade e imprecisão na construção do sentido.

Não estamos diante, então, de uma discussão sobre a construção de teorias nem de uma análise de expressões (apenas) linguísticas. Referimo-nos na verdade a determinados usos conceituais, particularmente vagos, que foram aqui analisados devido a sua natureza duplamente problemática: 1) são simplistas enquanto argumentos explicativos dos fenômenos a que se referem; e 2) ocultam importantes dimensões sociopolíticas e, por isso, trazem consigo certo efeito ideológico.

Referimo-nos, desse modo, a um problema da construção conceitual, dos significados que tais conceitos tendem a evocar (e, de certo modo, perpetuar) junto aos interpretantes. Ou seja, não é apenas o conceito em si mesmo, enquanto fenômeno da linguagem, que nos ocupa aqui. Mas é, sobretudo, o seu uso pragmático em sala de aula como referência preferencial e manualizada de significado, como base de uma estratégia didática que vem sendo repetida e confirmada provavelmente há décadas.

\footnotetext{
${ }^{4}$ Aqui entendidas como as disciplinas chamadas de "Introdução à Administração", "Teoria Geral da Administração (I e II)", "Teorias Administrativas", "Evolução do Pensamento Administrativo", entre outras denominações.
} 
Assim, ficará claro ao longo deste texto que, via de regra, nossos livros Best-Sellers de introdução às teorias administrativas usados na graduação sofrem de um mal chamado hipergeneralizações: ao definirem "quase qualquer coisa", terminam por definirem coisa alguma.

\section{Sobre a construção de conceitos}

A discussão crítica em torno dos processos de conceituação em Administração já possui algumas décadas e tem se intensificado nos últimos anos. Guerreiro Ramos (1981, p. 69) já havia tratado de alguns aspectos problemáticos da constituição da teoria organizacional, alertando para o risco de ela vir a transformar-se numa "mera confusão de divagações abstratas, desprovidas de força e de direção", sobretudo no que diz respeito: 1) ao uso indiscriminado e mal ressignificado de terminologias oriundas de outros campos teóricos; e 2) a manutenção de uma matriz epistemológica de forte ênfase behaviorista.

A discussão específica sobre o conceito de Organização tem nos rendido abordagens interessantestambém. É o caso, por exemplo, do estudo de Matitz e Vizeu (2012), que o toma como um fenômeno social e historicamente (re)construído, que revela as respectivas estruturas sociais a que se referee que, por fim, destaca a necessidade de enfrentarmos o problema das escolhas léxicas feitas para a proposição de terminologias específicas na área.

Neste artigo, a abordagem teórico-analítica é de natureza semântica. Assumimos aqui que a construção de um Conceito nqualquer $\left(C_{n}\right)$ é um enunciado que possui uma estrutura semântica binária, ou seja, é composto por dois elementos relacionados entre si. Ele surge, portanto, da ligação entre "aquilo de que se fala" e "aquilo que se fala", atendendo à forma linguística $C_{n}:[A$ é $B]$, em que:

- A é o tópico, ou seja, do que se fala ou o que se conceitua;

- B é o veículo, ou seja, o que se fala ou o conceitopropriamente;

E, por fim, A e B relacionam-se semanticamente pelo verbo de ligação, ou seja, o verbo ser (quadro 1).

Quadro 1

Forma linguística de um Conceito $n$

\begin{tabular}{|l|}
\hline$C_{n}:[A$ é B] \\
\hline A: tópico \\
\hline é: verbo de ligação \\
\hline B: veículo \\
\hline
\end{tabular}

Fonte: Elaborado pelo autor

Evidentemente que, com tal definição de partida, estamos nos limitando às conceituações diretas, ou seja, àquelas em que a associação semântica dá-se direta e explicitamente.

Aderindo à descrição de Benveniste (1991), segundo a qual a língua (enquanto sistema orgânico de signos) caracteriza-se pela integração de dois elementos delimitados através das relações que os unem, entendemos que um $C_{n}$ caracteriza-se também por uma dupla dimensão:

1. Dimensão Paradigmática: refere-se aos eixos verticais nos quais ocorrem seleções do léxico a partir de um paradigma. 
Exemplos: João é arquiteto.

João é médico.

João é musicista.

O paradigma é a classe ou categoria semântica dos itens lexicais que compõem o tópico ou o veículo. Temos, nos exemplos acima, variações no eixo paradigmático do enunciado, considerando o paradigma das profissões como veículo. O paradigma dos indivíduos ou profissionais ficou invariável (fixou-se o tópico "João").

2. Dimensão Sintagmática: representada pelas variações possíveis no eixo horizontal, ou seja, na organização sintática e semântica realizada com o léxico escolhido na frase.

Exemplos: João é arquiteto.

João poderia ser arquiteto.

João detesta arquitetos.

Os exemplos acima ilustram variações no eixo sintagmático do enunciado, responsável direto pela produção de uma proposta de significado, em detrimento de muitas outras, mantendo-se ainda fixado o tópico do enunciado ("João"). Embora a variação nos verbos e seus modalizadores seja uma ocorrência do plano paradigmático, é dessacombinação de léxicos que se elaborao sintagma, de uma forma não aleatória,estruturando-se, assim, a frase.

Foi Saussure quem primeiramente tratou das relações sintagmáticas e paradigmáticas nas sentenças, ao propor suas conhecidas dicotomias. ${ }^{5}$ As relações sintagmáticas baseiam-se no próprio caráter linear do signo linguístico: é impossível a pronúncia simultânea de dois elementos. Há, portanto, uma sucessão linear dos elementos da língua - a chamada "cadeia da fala". As relações paradigmáticas surgem da associação que o usuário da língua faz com termos que não estão presentes no discurso, mas com os quais os termos que estão presentes no discurso se comparam de variadas formas. A relação paradigmática é uma relação associativa com elementos que estão fora do discurso; portanto, fora do plano sintagmático. Enquanto o paradigma diz respeito ao conjunto de elementos similares,o sintagma é o encadeamento de tais elementos (SAUSSURE,1969, p. 142-143; CARVALHO, 2005, p. 101). Esclarece-nos Pietroforte (2003, p. 88):

Há, portanto, relações de combinação entre ossignos. A essas relações, Saussure chama de sintagmáticas, do grego syntagma, que quer dizer "coisa posta em ordem". Além das relações sintagmáticas, baseadas na combinação, há também relações baseadas na seleção dos elementos que são combinados. Apresentando algo em comum, um signo pode ser associado a outros signos por, pelo menos, três modos: por meio de seu significado, com seus antônimos e sinônimos; pormeio de seu significante, com imagens acústicas semelhantes; e por meio deoutros signos, em processos morfológicos comuns.

É fácil perceber queda combinação de variações no paradigma e no sintagma surgem incontáveis possibilidades semânticas para os enunciados. De modo que a construção dos enunciados conceituais depende tanto do componente paradigmático - como categoria semântica fincada no sistema lexical (palavra) -, quanto dos processos predicativos realizados em nível sintagmático (sentença).

${ }^{5}$ As chamadas dicotomias saussureanas são: diacronia $\mathrm{x}$ sincronia; língua $\mathrm{x}$ fala; significado $\mathrm{x}$ significante; sintagma $\mathrm{x}$ paradigma. Sobre elas, o célebre linguista suíço fundamentou seu estruturalismo linguístico. 
Um aspecto importante inerente à constituição dos paradigmas nos enunciados é que, enquanto processos de categorização semântica, eles possuem uma relação hierárquica com os itens lexicais que o compõem, definida como uma relação semântico-cognitiva do tipo hiponímia-hiperonímia. Uma palavra ou expressão é um hipônimo ou hiperônimo de outra a depender de como se relacionam quanto à inclusão categorial. Podemos dizer, por exemplo, que "fruta" é hipônimo de "alimento", mas é hiperônimo de "limão", e assim por diante. Portanto, o paradigma e os seus itens lexicais estão em níveis categoriais diferentes. O paradigma é hiperônimo do item lexical, de maneira que o item lexical será sempre um elemento que é exemplar de uma categoria semântica (o paradigma).

Como veremos adiante, nossa forma $C_{n}$ : $[A$ é $B]$ é a base de definição do eixo sintagmático das sentenças que submetemos à análise. Mas é importante notar que, embora seja no sintagma que tais conceitos apresentamse frágeis, será justamente através de testes no eixo paradigmático do tópico que demonstraremos tal fragilidade. Isso porque a vagueza semântica existente nos conceitos analisados permite a adição ao sintagma de paradigmas construídos através de categorias semânticas absurdamente amplas - como demonstraremos o que termina por caracterizar tais conceitos como "definições de quase qualquer coisa". Como já dissemos, estamos chamando este padrão de definição identificado na nossa pesquisa de hipergeneralização conceitual $^{6}$, prática discursiva que, caracterizada por excessiva amplitude, tende a certo esvaziamento e dispersão conceitual de significado relevante e útil.

Escolhemos, para analisar, um dos tópicos mais relevantes e básicos no ensino dos estudos e que, por isso mesmo, éentendido aqui como um conceito-chave. Neste sentido, devemos observar que a definição de conceito-chave atende a duas características básicas dentro do conjunto conceitual de que faz parte:

1. É apresentado de partida; e

2. É referenciado explícita ou implicitamente como base para a maior parte dos demais conceitos que se seguem.

O conceito-chave cuja análise demonstraremos a seguir diz respeito ao fenômeno básico de estudo da Administração: as organizações. Portanto, uma vez definido o tópico, a construção do Conceito $n$, antes definida como $C_{n}:[A e ́ B]$, fica assim especificado para a nossa análise: Organização(ões) é/são $B$, onde $B$ é o veículo (quadro 2).

Quadro 2

Forma linguística de um Conceito $n$, após definição do tópico

\begin{tabular}{|c|}
\hline$C_{n}:[A$ é B] \\
\hline Organização(ões) é/são B \\
\hline B: veículo \\
\hline
\end{tabular}

Fonte: Elaborado pelo autor

6 O leitor poderá encontrar o termo hipergeneralização usado em psicologia, especificamente na terapia cognitivo-comportamental, nesse caso para indicar a tendência comportamental de transformar a percepção da ocorrência de um evento em um padrão determinístico: "Se for verdade em um caso, aplica-se a todos os casos, mesmo quelevemente similar. Se uma vez for verdade no passado, será sempreassim. A pessoa enxerga um único evento negativo como um padrão dederrota que nunca vai terminar. Um raio nunca para de cair no mesmolugar." (ZUGMAN, 2011) 


\section{Conceitos e contexto}

É importante ainda considerarmos que assituações de aprendizagem em sala de aula não são meros processos de transferência de conceitos entre professor e aluno,embora, diga-se de passagem, toda a abordagem sobre comunicação nestes mesmos livros ainda esteja presa ao ultrapassado modelo emissor-receptor (mas isso é assunto para outra pesquisa).

Isso significa que os conceitos-chave apreciados neste artigo não devem ser tomados como construções de linguagem independentes de suas condições de produção e ressignificação. Eles não são simples "letras mortas", algo que apenas está escrito em algum lugar, mas um fenômeno linguístico-cognitivo de natureza semântico-pragmática. Numa palavra, os conceitos-chave nos livros didáticos são referências para as práticas de elaboração conceitual para os formandos.

Naturalmente que a construção do conhecimento em sala de aula ocorre nas especificidades das ressignificações linguístico-pragmáticas dos conceitos trabalhados. Porém, mesmo que tais experiências de aprendizagem sejam únicas, elas não escapam da influência dos padrões interpretativos defendidos consciente ou inconscientemente pelo professor, através dos mecanismos didáticos de ensino e avaliação.

O que nos leva a reconhecer que a aprendizagem do aluno é afetada, necessariamente, pela referência conceitual apresentada pelos manuais didáticos, cujo uso é indicado ou referendado pelo docente. É assim que o aluno, embora construa criativamente suas próprias elaborações, será constantemente estimulado a reproduzir o que leu na bibliografia da disciplina. Que o digam as provas de fim de semestre.

\section{Construindo o corpus da pesquisa: manuais best-sellers de introdução às teorias administrativas}

A escolha de uma pesquisa bibliográfica como estratégia metodológica de investigação de campo foi uma consequência natural da nossa problematização, que toma como fenômeno sob observação os conceitoschave presentes nos livros-textos, usados em aulas de disciplinas introdutórias de cursos de graduação em Administração no Brasil.

Desse modo, selecionamos os livros mais usados nos cursos das maiores e melhores IES do país, para que tivéssemos em mãos um material de grande alcance de influência na formação dos administradores brasileiros em nível de graduação e, ao mesmo tempo, considerássemos o que há de formalmente reconhecido como mais apropriado ao ensino de Administração nos cursos de graduação, para que não estivéssemos falando de experiências de formação profissional desprestigiadas e/ou isoladas. Para chegarmos a este conjunto de livros, seguimos as seguintes etapas:

Etapa 1: Com base em 5 rankings de melhores e maiores IES com cursos de Administração, construímos uma relação com 31 IES (INEP, 2008; GUIA DO ESTUDANTE, 2008).

Etapa 2: Contatamos cada uma das IES em busca das bibliografias adotadas nas disciplinas introdutórias de Administração. Totalizamos 27 bibliografias (extraídas dos planos de curso ou programas de 27 disciplinas de 10 cursos), chegando a 200 ocorrências de referências bibliográficas que, excluídas as repetições, dizem respeito a 89 livros.

Etapa 3: Dentre estes 89 livros, identificamos 65 manuais de introdução às teorias administrativas, que aparecem em 164 ocorrências de referências bibliográficas (dentre as 200 listadas na etapa 2). A esta lista de 89 livros aplicamos um filtro para ocorrência mínima de 2 vezes, ou seja, foram descartados os livros que só foram encontrados em uma única bibliografia (dentre as 27 listadas na etapa 2). Chegamos, então, aos 35 livros adotados em pelo menos 2 bibliografias/disciplinas 
(aproximadamente 54\% dos livros), que aparecem em 133 ocorrências de referências bibliográficas (cerca de $81 \%$ das ocorrências) dentre as 164 ocorrências de referências bibliográficas de todos os manuais de introdução às teorias administrativas.

Etapa 4: Foi feita, então, uma classificação decrescente desta relação final de livros, pelo percentual de ocorrências do livro entre o total de bibliografias/disciplinas.

Etapa 5: Em seguida, com a intenção de diminuir em parte uma possível dissonância entre a informação constante nas bibliografias e o uso efetivo dos manuais nas salas de aula, realizamos uma consulta junto aos 153 professores/pesquisadores cadastrados na divisão de Estudos Organizacionais (EOR) da ANPAD. Enviamos a eles um e-mail perguntando, àqueles que lecionaram ou lecionam disciplinas introdutórias à Administração, em cursos de graduação em Administração, qual(is) o(s) livros(s) texto(s) adotado(s) na(s) disciplina(s). Dos 153 consultados, 45 responderam ao e-mail, sendo que, dentre eles, 23 responderam às questões por estarem no perfil de experiência docente solicitado. Os 23 professores/pesquisadores informaram um total de 48 ocorrências de referências bibliográficas que, excluídas as repetições, dizem respeito a 19 livros.

Etapa 6: Por fim, fizemos dois movimentos para fechar nossa lista de livros. Primeiro, comparamos as duas seleções e verificamos que, dentre os livros listados na segunda, apenas um livro juntou-se ao grupo dos mais citados na primeira. Isso nos deu um indicativo de que estávamos diante de uma amostra de livros bem representativa do que vem sendo usado nos últimos quinze anos nas salas de aula dos cursos de graduação em administração no Brasil. Segundo, para chegar efetivamente à lista final combinamos as duas seleções. Dos 19 livros citados na segunda seleção, 12 já constavam entre os 35 da primeira. Como todos os 7 livros que não constavam também na primeira seleção só apareceram na segunda seleção em 1 ocorrência bibliográfica, eles foram naturalmente desprezados, atendendo ao mesmo critério de livros que constassem ao menos em 2 ocorrências, já descrito na etapa 3. Então, somamos as 41 ocorrências desses 12 livros, identificados como comuns a ambas as seleções, respectivamente as ocorrências que já haviam sido totalizadas na primeira seleção. Reordenamos a lista, agora compondo os novos dados, novamente em ordem decrescente pelo total de ocorrências do livro (tabela 1). Desta relação final, selecionamos os dez primeiros livros aos quais tivemos acesso para compormos o corpus para a análise feita neste artigo.

Tabela 1

Relação dos livros extraídos da bibliografia das disciplinas sobre Teorias Administrativas e Introdução às teorias administrativas nos cursos de graduação em Administração combinada com os livros extraídos de consulta feita a professores/pesquisadores da Divisão Acadêmica EOR da ANPAD -mínimo de 2 ocorrências, em ordem decrescente de total de ocorrências.

\begin{tabular}{|c|c|c|c|}
\hline Referência & $\begin{array}{l}\text { Ocor. } \\
\text { Bib. }\end{array}$ & $\begin{array}{l}\text { Ocor. } \\
\text { Anpad }\end{array}$ & $\begin{array}{l}\text { Total } \\
\text { Ocor. }\end{array}$ \\
\hline MAXIMIANO, A. C. A. Introdução à administração. São Paulo: Atlas, 2007. & 13 & 5 & 18 \\
\hline $\begin{array}{l}\text { MAXIMIANO, A. C. A. Teoria Geral da Administração: Da Revolução Urbana à } \\
\text { Revolução Digital. São Paulo: Atlas, } 2005 \text {. }\end{array}$ & 9 & 6 & 15 \\
\hline
\end{tabular}




\begin{tabular}{|c|c|c|c|}
\hline $\begin{array}{l}\text { MOTTA, F. C. P.; VASCONCELOS, I. F. G. Teoria Geral da Administração. São } \\
\text { Paulo: Thomson, } 2002 .\end{array}$ & 3 & 10 & 13 \\
\hline $\begin{array}{l}\text { CHIAVENATO, I. Introdução à teoria geral da administração. Rio de Janeiro: } \\
\text { Elsevier, } 2003 .\end{array}$ & 6 & 6 & 12 \\
\hline KWASNICKA, E. L. Introdução à Administração. São Paulo: Atlas, 1995. & 9 & - & 9 \\
\hline $\begin{array}{l}\text { BATEMAN, T. S., SNELL, S. A. Administração: construindo vantagem } \\
\text { competitiva. São Paulo: Atlas, } 1998 .\end{array}$ & 4 & 4 & 8 \\
\hline $\begin{array}{l}\text { CHIAVENATO, I. Teoria geral da administração. São Paulo: Makron Books, } \\
\text { 1995. v. } 1 \text { e } 2 \text {. }\end{array}$ & 3 & 4 & 7 \\
\hline $\begin{array}{l}\text { ROBBINS, S. P. Administração: mudanças e perspectivas. São Paulo: Saraiva, } \\
2000 .\end{array}$ & 5 & 1 & 6 \\
\hline STONER, J.; FREEMAN, E. Administração; Rio de Janeiro: Prentice-Hall, 2000. & 6 & - & 6 \\
\hline BERNARDES, C. Teoria Geral das organizações. São Paulo: Atlas, 1997. & 5 & - & 5 \\
\hline $\begin{array}{l}\text { CHIAVENATO, I. Administração: teoria, processo e prática. São Paulo: Makron } \\
\text { Books, } 1994 .\end{array}$ & 4 & 1 & 5 \\
\hline MONTANA, P.; CHARNOV, B. Administração. São Paulo: Saraiva, 1998. & 5 & - & 5 \\
\hline $\begin{array}{l}\text { WOMACK, J. P.; ROOS, D.; JONES, D. T. A máquina que mudou o mundo. Rio } \\
\text { de Janeiro: Campus, } 1992 .\end{array}$ & 5 & - & 5 \\
\hline $\begin{array}{l}\text { HAMPTON, D. R. Administração Contemporânea: teoria, prática, casos. São } \\
\text { Paulo: Makron Books, } 1990 .\end{array}$ & 4 & - & 4 \\
\hline $\begin{array}{l}\text { LONGENECKER, J. G. Introduçãoà administração: uma abordagem } \\
\text { comportamental. São Paulo: Atlas, } 1981 .\end{array}$ & 4 & - & 4 \\
\hline MORGAN, G. Imagens da organização. São Paulo: Atlas, 1997. & 3 & 1 & 4 \\
\hline $\begin{array}{l}\text { CHIAVENATO, I. Administração de empresas: uma abordagem contingencial. } \\
\text { São Paulo: Makron Books, } 1994 .\end{array}$ & 2 & - & 3 \\
\hline $\begin{array}{l}\text { CHIAVENATO, I. Administração nos novos tempos. 2.ed. Rio de Janeiro: } \\
\text { Campus, } 1999 .\end{array}$ & 2 & 1 & 3 \\
\hline DAFT, R. L. Administração. Rio de Janeiro: LTC, 2003. & 2 & 1 & 3 \\
\hline $\begin{array}{l}\text { FERREIRA, A. A.; REIS, A. C. F.; PEREIRA, M. I. Gestão Empresarial: de Taylor } \\
\text { aos nossos dias. São Paulo: Pioneira, } 1997 .\end{array}$ & 3 & - & 3 \\
\hline $\begin{array}{l}\text { GIBSON, J. e outros. Organizações: processo e estrutura. São Paulo: Atlas, } \\
1981 .\end{array}$ & 3 & - & 3 \\
\hline GUIDA, F. A. Panorama geral da administração. Rio de Janeiro: Campus, 1980. & 3 & - & 3 \\
\hline $\begin{array}{l}\text { KOONTZ, H.; O'DONNELL, C. Fundamentos da administração. São Paulo: } \\
\text { Pioneira, } 1981 .\end{array}$ & 3 & - & 3 \\
\hline
\end{tabular}




\begin{tabular}{|c|c|c|c|}
\hline $\begin{array}{l}\text { LACOMBE, F.; HEILBORN, G. Administração: princípios e tendências. São } \\
\text { Paulo: Saraiva, } 2003 .\end{array}$ & 3 & - & 3 \\
\hline RAMOS, A. G. Administração e contexto brasileiro. Rio de Janeiro: FGV, 1988. & 3 & - & 3 \\
\hline SCHERMERHORN, J. R. Administração. 5.ed. Rio de Janeiro: LTC, 1999. & 3 & - & 3 \\
\hline DAFT, R. L. Teoria e projeto das organizações. Rio de Janeiro: LTC, 1999. & 2 & - & 2 \\
\hline $\begin{array}{l}\text { GEORGE JUNIOR, C. S. História do pensamento administrativo. São Paulo: } \\
\text { Cultrix, } 1974 .\end{array}$ & 2 & - & 2 \\
\hline LODI, J. B. História da administração. São Paulo: Pioneira, 1982. & 2 & - & 2 \\
\hline $\begin{array}{l}\text { MEGGINSON, L. C. et al. Administração: conceitos e aplicações. São Paulo: } \\
\text { Harbra, } 1986 .\end{array}$ & 2 & - & 2 \\
\hline $\begin{array}{l}\text { MORAES, A. M. P. de. Iniciação ao estudo da administração. São Paulo: } \\
\text { Makron, } 2001 .\end{array}$ & 2 & - & 2 \\
\hline $\begin{array}{l}\text { MOTTA, F. C. P. Introdução à teoria geral da administração. São } \\
\text { Paulo:Pioneira, } 1991 .\end{array}$ & 2 & - & 2 \\
\hline MOTTA, F. C. P. Teoria geral da administração. São Paulo: Pioneira 1966 & 2 & - & 2 \\
\hline $\begin{array}{l}\text { MOTTA, P. R.Gestão Contemporânea: a ciência e a arte de ser dirigente. Rio } \\
\text { de Janeiro: Record, } 1995 .\end{array}$ & 2 & - & 2 \\
\hline $\begin{array}{l}\text { WALT, M. O método Deming de Administração. São Paulo: Marques - Saraiva, } \\
\text { 1989. }\end{array}$ & 2 & - & 2 \\
\hline Total de Ocorrências de Referências Bibliográficas & 133 & 41 & 174 \\
\hline
\end{tabular}

Fonte: Moura (2009).

Definido o corpusda pesquisa, foi feita uma busca nos livros que o compuseram (tabela 1), seguindo a ordem de classificação por quantidade de ocorrências bibliográficas, até que se identificassem na leitura um total de dez enunciados (ou conjuntos de enunciados) que indicassem conceituação sobre o tópico em análise, ou seja, os enunciados construídos na forma Organização(ões) é/são $B$.

Embora vários trechos identificados nos livros selecionados trouxessem consigo algum tipo de definição implícita ou pressuposta, preocupamo-nos em destacar especificamente todas as definições diretas, sobretudo em função da força semântica que elas costumam possuir, porque, geralmente, estão destacadas e grifadas pelos seus próprios autores. Selecionamos dez dentre eles para a nossa análise, resultando na relação de conceitos-chave sobre Organizações abaixo (quadro 3). 


\section{Quadro 3}

\section{Conceitos-chave sobre o tópico Organizações}

(C.01) "Organizações são sistemas de recursos que procuram realizar objetivos ou conjunto de objetivos [...]. [Possuem também] divisão de trabalho e processos de transformação. [...] São grupos sociais deliberadamente orientados para a realização de objetivos ou finalidades." (MAXIMIANO, 2007, p. 130)

(C.02) "Uma organização é um sistema de recursos que procura realizar algum tipo de objetivo (ou conjunto de objetivos). Além de objetivos e recursos, as organizações têm dois outros componentes importantes: processos de transformação e divisão do trabalho." (MAXIMIANO, 2005, p. 4)

(C.03) Organizações são (1) entidades sociais que (2) são dirigidas por metas, (3) são desenhadas como sistemas de atividades deliberadamente estruturados e coordenados e (4) são ligadas ao ambiente externo. [...] Uma organização existe quando as pessoas interagem para realizar funções essenciais que auxiliam a alcançar metas. (DAFT, 2003, p. 11)

(C.04) Organização: Duas ou mais pessoas trabalhando juntas e de modo estruturado para alcançar um objetivo específico ou um conjunto de objetivos. (STONER e FREEMAN, 2000, p. 4)

(C.05) "Organização é um grupo de pessoas que se constitui de forma organizada para atingir objetivos comuns. Incluem-se nesta definição as empresas, universidades, hospitais, escolas, creches, associações culturais, partidos políticos, sindicatos, clubes, condomínios, cooperativas, famílias, organizações não governamentaisnão-governamentais, associações de classes profissionais, corporações militares, associações de moradores de bairro, entre outros. Quase tudo, portanto, é feito por meio das organizações." (LACOMBE e HEILBORN, 2003, p. 13)

(C.06) "Organização é um arranjo sistemático de duas ou mais pessoas que cumprem papéis formais e compartilham um propósito comum." (ROBBINS, 2005, p. 31)

(C.07) "Uma organização é um sistema administrado, projetado e operado para atingir determinado conjunto de objetivos. [...] Uma organização não é um grupo aleatório de pessoas que estão juntas por acaso. Ela se estabelece conscientemente e formalmente para atingir certos objetivos que seus membros não estariam capacitados a atingir por si sós." (BATEMAN e SNELL, 1998, p. 33)

(C.08) “Organização é uma associação de pessoas caracterizada por: 1) ter a função de produzir bens, prestar serviços à sociedade e atender necessidades de seus próprios participantes; 2) possuir uma estrutura formada por pessoas que se relacionam colaborando e dividindo o trabalho para transformar insumos em bens e serviços; 3) ser perene no tempo." (BERNARDES, 1997, p. 17)

(C.09) "As organizações surgem dessa necessidade primária de cooperação. Qualquer organização é composta de: - duas ou mais pessoas; - que interagem entre si, através de relações recíprocas; para atingir objetivos comuns." (CHIAVENATO, 1982, p. 35)

(C.10) "Uma empresa nada mais é do que um grupo, como o já definimos no corpo de nossa obra. A maneira em que os grupos são compostos, dentro do ponto de vista empresarial, podem variar em estrutura, organização, tamanho, objetivos, direitos e obrigações." (KWASNICKA, 1995, p. 235)

Fonte: Elaborado pelo autor 


\section{Analisando hipergeneralizações: organizações são "quaisquer possíveis coletividades humanas"}

Como dissemos, nossa análise consiste basicamente na demonstração de que os conceitos-chave identificados no corpusapresentam excessiva vagueza semântica, que pode ser observada na construção do eixo sintagmático das sentenças correspondentes.

Para realizar tal demonstração, definimos arbitrariamente um paradigma $P$ qualquer para o tópico Organizações, caracterizado a partir de uma categoria semântica denominada: "quaisquer possíveis coletividades humanas" (quadro 4).

\section{Quadro 4}

\section{Conjunto arbitrário de léxicos integrantes do} paradigma $\boldsymbol{P}$ "quaisquer possíveis coletividades humanas"

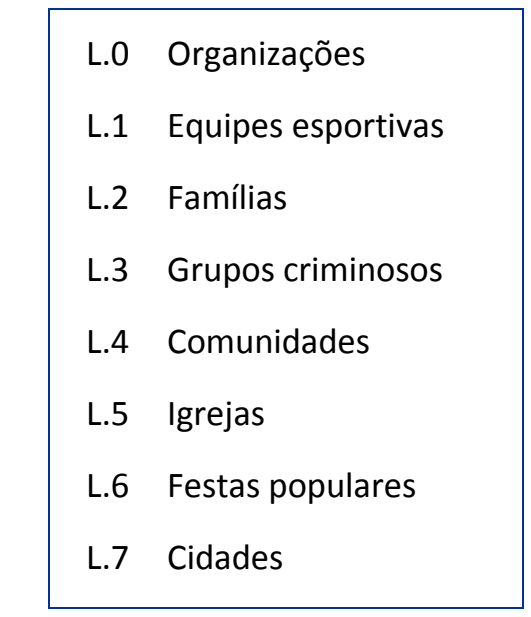

Fonte: Elaborado pelo autor

Importante notar que a abertura semântica em $P$ é proposital e não se prende necessariamente a algum critério homogêneo (além da presença de seres humanos) para a definição do seu conjunto de léxicos integrantes, justamente porque seu uso atende à finalidade de demonstrar a excessiva amplitude paradigmática que a fragilidade dos sintagmas proporciona ao tópico.

Definido o paradigma $P$ e, juntamente com ele, um breve conjunto de léxicos integrantes (inclusive o tópico que é listado como L.0), a análise dos conceitos consiste simplesmente na seleção dos léxicos integrantes de $P$, para recompor o conceito e verificar sua consistência semântica. Para cada nova seleção, obtém-se um novo conceito $N C_{n}$, como pode ser observado nos quadros a seguir (Quadros 5 a 14). 
Quadro 5

Aplicação de C.01 (MAXIMIANO, 2004, p. 130) ao paradigma $P$

\begin{tabular}{|c|c|c|c|}
\hline$c_{n}:$ & {$[A$} & \multirow{8}{*}{ são } & B] \\
\hline NC.01.1 & Equipes esportivas & & \multirow{7}{*}{$\begin{array}{l}\text { sistemas de recursos que procuram realizar objetivos ou } \\
\text { conjunto de objetivos. [...] Possuem também divisão de } \\
\text { trabalho e processos de transformação. [...] São grupos } \\
\text { sociais deliberadamente orientados para a realização de } \\
\text { objetivos ou finalidades. }\end{array}$} \\
\hline NC.01.2 & Famílias & & \\
\hline NC.01.3 & Grupos criminosos & & \\
\hline NC.01.4 & Comunidades & & \\
\hline NC.01.5 & Igrejas & & \\
\hline NC.01.6 & Festas populares & & \\
\hline NC.01.7 & Cidades & & \\
\hline
\end{tabular}

Fonte: Elaborado pelo autor

Quadro 6

Aplicação de C.02 (MAXIMIANO, 2005, p. 4) ao paradigma $P$

\begin{tabular}{|c|c|c|c|}
\hline$C_{n}:$ & {$[A$} & \multirow{8}{*}{ são } & $B]$ \\
\hline NC.02.1 & Equipes esportivas & & \multirow{7}{*}{$\begin{array}{l}\text { um sistema de recursos que procura realizar algum tipo } \\
\text { de objetivo (ou conjunto de objetivos). Além de } \\
\text { objetivos e recursos, as organizações têm dois outros } \\
\text { componentes importantes: processos de transformação e } \\
\text { divisão do trabalho. }\end{array}$} \\
\hline NC.02.2 & Famílias & & \\
\hline NC.02.3 & Grupos criminosos & & \\
\hline NC.02.4 & Comunidades & & \\
\hline NC.02.5 & Igrejas & & \\
\hline NC.02.6 & Festas populares & & \\
\hline NC.02.7 & Cidades & & \\
\hline
\end{tabular}

Fonte: Elaborado pelo autor 


\section{Quadro 7}

\section{Aplicação de C.03 (DAFT, 2003, p. 11) ao paradigma $P$}

\begin{tabular}{|c|c|c|c|}
\hline$C_{n}:$ & {$[A$} & \multirow{8}{*}{ são } & B] \\
\hline NC.03.1 & Equipes esportivas & & \multirow{7}{*}{$\begin{array}{l}\text { (1) entidades sociais que (2) são dirigidas por metas, (3) são } \\
\text { desenhadas como sistemas de atividades deliberadamente } \\
\text { estruturados e coordenados e (4) são ligadas ao ambiente } \\
\text { externo. [...] Uma organização existe quando as pessoas } \\
\text { interagem para realizar funções essenciais que auxiliam a } \\
\text { alcançar metas. }\end{array}$} \\
\hline NC.03.2 & Famílias & & \\
\hline NC.03.3 & Grupos criminosos & & \\
\hline NC.03.4 & Comunidades & & \\
\hline NC.03.5 & Igrejas & & \\
\hline NC.03.6 & Festas populares & & \\
\hline NC.03.7 & Cidades & & \\
\hline
\end{tabular}

Fonte: Elaborado pelo autor

Quadro 8

Aplicação de C.04 (STONER; FREEMAN, 2000, p. 4) ao paradigma $P$

\begin{tabular}{|c|c|c|c|}
\hline$C_{n}:$ & {$[A$} & \multirow{8}{*}{ são } & B] \\
\hline NC.04.1 & Equipes esportivas & & \multirow{7}{*}{$\begin{array}{l}\text { Duas ou mais pessoas trabalhando juntas e de modo } \\
\text { estruturado para alcançar um objetivo específico ou um } \\
\text { conjunto de objetivos. }\end{array}$} \\
\hline NC.04.2 & Famílias & & \\
\hline NC.04.3 & Grupos criminosos & & \\
\hline NC.04.4 & Comunidades & & \\
\hline NC.04.5 & Igrejas & & \\
\hline NC.04.6 & Festas populares & & \\
\hline NC.04.7 & Cidades & & \\
\hline
\end{tabular}

Fonte: Elaborado pelo autor 
Quadro 9

Aplicação de C.05 (LACOMBE; HEILBORN, 2003, p. 13) ao paradigma $P$

\begin{tabular}{|c|c|c|c|}
\hline$C_{n}:$ & {$[A$} & \multirow{8}{*}{ são } & B] \\
\hline NC.05.1 & Equipes esportivas & & um grupo de pessoas que se constitui de forma \\
\hline NC.05.2 & Famílias & & $\begin{array}{l}\text { organizada para atingir objetivos comuns. Incluem-se } \\
\text { nesta definição as empresas, universidades, hospitais, }\end{array}$ \\
\hline NC.05.3 & Grupos criminosos & & escolas, creches, associações culturais, partidos \\
\hline NC.05.4 & Comunidades & & famílias, organizações não-governamentais, associações \\
\hline NC.05.5 & Igrejas & & $\begin{array}{l}\text { de classes profissionais, corporações militares, } \\
\text { associações de moradores de bairro, entre outros. }\end{array}$ \\
\hline NC.05.6 & Festas populares & & Quase tudo, portanto, é feito por meio das \\
\hline NC.05.7 & Cidades & & \\
\hline
\end{tabular}

Fonte: Elaborado pelo autor

Quadro 10

Aplicação de C.06 (ROBBINS, 2005, p. 31) ao paradigma $P$

\begin{tabular}{|c|c|c|c|}
\hline$C_{n}:$ & {$[A$} & \multirow{8}{*}{ são } & B] \\
\hline NC.06.1 & Equipes esportivas & & \multirow{7}{*}{$\begin{array}{l}\text { um arranjo sistemático de duas ou mais pessoas que } \\
\text { cumprem papéis formais e compartilham um propósito } \\
\text { comum. }\end{array}$} \\
\hline NC.06.2 & Famílias & & \\
\hline NC.06.3 & Grupos criminosos & & \\
\hline NC.06.4 & Comunidades & & \\
\hline NC.06.5 & Igrejas & & \\
\hline NC.06.6 & Festas populares & & \\
\hline NC.06.7 & Cidades & & \\
\hline
\end{tabular}

Fonte: Elaborado pelo autor 


\section{Quadro 11}

\section{Aplicação de C.07 (BATEMAN; SNELL, 1998, p. 33) ao paradigma $P$}

\begin{tabular}{|c|c|c|c|}
\hline$C_{n}:$ & {$[A$} & \multirow{8}{*}{ são } & B] \\
\hline NC.07.1 & Equipes esportivas & & \multirow{7}{*}{$\begin{array}{l}\text { umsistema administrado projetado e operado para } \\
\text { atingir determinado conjunto de objetivos. [...] Uma } \\
\text { organização não é um grupo aleatório de pessoas que } \\
\text { estão juntas por acaso. Ela se estabelece } \\
\text { conscientemente e formalmente para atingir certos } \\
\text { objetivos que seus membros não estariam capacitados a } \\
\text { atingir por si sós. }\end{array}$} \\
\hline NC.07.2 & Famílias & & \\
\hline NC.07.3 & Grupos criminosos & & \\
\hline NC.07.4 & Comunidades & & \\
\hline NC. 07.5 & Igrejas & & \\
\hline NC.07.6 & Festas populares & & \\
\hline NC.07.7 & Cidades & & \\
\hline
\end{tabular}

Fonte: Elaborado pelo autor

Quadro 12

\section{Aplicação de C.08 (BERNARDES, 1997, p. 17) ao paradigma $P$}

\begin{tabular}{|c|c|c|c|}
\hline$C_{n}:$ & {$[A$} & \multirow{8}{*}{ são } & B] \\
\hline NC.08.1 & Equipes esportivas & & \multirow{7}{*}{$\begin{array}{l}\text { uma associação de pessoas caracterizada por: 1) ter a } \\
\text { função de produzir bens, prestar serviços à sociedade e } \\
\text { atender necessidades de seus próprios participantes; } 2 \text { ) } \\
\text { possuir uma estrutura formada por pessoas que se } \\
\text { relacionam colaborando e dividindo o trabalho para } \\
\text { transformar insumos em bens e serviços; } 3 \text { ) ser perene } \\
\text { no tempo. }\end{array}$} \\
\hline NC.08.2 & Famílias & & \\
\hline NC.08.3 & Grupos criminosos & & \\
\hline NC.08.4 & Comunidades & & \\
\hline NC.08.5 & Igrejas & & \\
\hline NC.08.6 & Festas populares & & \\
\hline NC.08.7 & Cidades & & \\
\hline
\end{tabular}

Fonte: Elaborado pelo autor 


\section{Quadro 13}

\section{Aplicação de C.09 (CHIAVENATO, 1982, p. 35) ao paradigma $P$}

\begin{tabular}{|c|c|c|c|}
\hline$C_{n}:$ & {$[A$} & \multirow{8}{*}{ são } & B] \\
\hline NC.09.1 & Equipes esportivas & & \multirow{7}{*}{$\begin{array}{l}\text { composta de: - duas ou mais pessoas; - que interagem } \\
\text { entre si, através de relações recíprocas; - para atingir } \\
\text { objetivos comuns. }\end{array}$} \\
\hline NC.09.2 & Famílias & & \\
\hline NC.09.3 & Grupos criminosos & & \\
\hline NC.09.4 & Comunidades & & \\
\hline NC.09.5 & Igrejas & & \\
\hline NC.09.6 & Festas populares & & \\
\hline NC.09.7 & Cidades & & \\
\hline
\end{tabular}

Fonte: Elaborado pelo autor

Aplicação de C.10 (KWASNICKA, 1995, p. 235) ao paradigma $P$

\begin{tabular}{|c|c|c|c|}
\hline$C_{n}:$ & {$[A$} & \multirow{8}{*}{ são } & B] \\
\hline NC.10.1 & Equipes esportivas & & \multirow{7}{*}{$\begin{array}{l}\text { um grupo, como o já definimos no corpo de nossa obra. } \\
\text { A maneira em que os grupos são compostos, dentro do } \\
\text { ponto de vista empresarial, podem variar em estrutura, } \\
\text { organização, tamanho, objetivos, direitos e obrigações." } \\
\text { (KWASNICKA, 1995, p. 235) }\end{array}$} \\
\hline NC.10.2 & Famílias & & \\
\hline NC.10.3 & Grupos criminosos & & \\
\hline NC.10.4 & Comunidades & & \\
\hline NC.10.5 & Igrejas & & \\
\hline NC.10.6 & Festas populares & & \\
\hline NC.10.7 & Cidades & & \\
\hline
\end{tabular}

Fonte: Elaborado pelo autor

Como pode ser observado nos quadros acima (quadros 5 a 14), para a maioria dos NCs surgidos a partir da aplicação do paradigma $P$ aos enunciados, identificados no corpus como conceitos-chave sobre o tópico Organizações, o significado surgido é tão aplicável quanto o é para o NC.0 correspondente (Organizações). 
Vale destacarparticularmente algumas das descrições, segundo as quais Organizações são: grupos sociais; sistemas de recursos; orientadas para realizar objetivos; ligadas ao ambiente externo; arranjos de pessoas que cumprem papéis formais. É difícil encontrarmos alguma coletividade humana que não se caracterize assim.

Uma vez que o Paradigma $P$ é uma categoria semântica definida como "quaisquer possíveis coletividades humanas", e que a maior parte dos léxicos que o integram preservaram a estrutura sintática e semântica do sintagma, que compõe cada um dos conceitos-chave em que foram colocados na condição de veículo, podemos afirmar que aquela categoria semântica pode ser igualmente usada como veículo (em substituição aos seus léxicos integrantes), sem que haja alterações relevantes de significado nos respectivos conceitoschave.

Desse modo, podemos dizer que, segundo o corpus analisado, Organizações são "quaisquer possíveis coletividades humanas" (quadro 15). Essa substituição atende ao princípio de relação categorial hiperonímiahiponímia, que caracteriza a definição de paradigmas, conforme já dissemos.

\section{Quadro 15}

Conceito $n$, derivado da aplicação do paradigma $P$

\begin{tabular}{|c|}
\hline Organização(ões) é/são $B$ \\
\hline B: veículo \\
\hline veículo = itens lexicais integrantes de $P$ \\
veículo $=P$ \\
\hline $\begin{array}{c}\text { Organizações são quaisquer possíveis coletividades humanas } \\
\text { (categoria semântica definidora de } P \text { ) }\end{array}$ \\
\hline
\end{tabular}

Fonte: Elaborado pelo autor

Então, como vimos, o novo Conceito $n$ surgido na maioria das aplicações do paradigma $P$ aos conceitoschave analisados, pode descrever uma empresa, mas também uma cidade, um jogo de futebol ou uma festa popular, por exemplo. Pode, enfim, descrever todos os itens lexicais que compõem o paradigma bem como outros tantos itens lexicais que poderiam, ainda, ser a ele adicionados.

Importante ainda considerar que, na medida em que o tópico Organizações corresponde a um conceito-chave dos livros analisados, a definição "Organizações são quaisquer possíveis coletividades humanas" torna-se um padrão semântico subjacente a toda discussão que se refira direta ou indiretamente ao tópico, apresentada naqueles livros. Trata-se de um conceito semanticamente encapsulado em todos os demais que são neles apresentados.

\section{Implicações do Amplo Uso de Hipergeneralizações ou em Busca de um Conceito Não hipergeneralista}

A esta altura, já está devidamente demonstrado que o que aqui estamos chamando de hipergeneralizaçãoé o padrão conceitual, para o tópico Organização, nos livros de introdução às teorias administrativas, usados nos 
cursos de Administração das maiores e mais importantes instituições de ensino superior do Brasil. Estamos falando de livros que vêm sendo usados junto aos alunos da área há vários anos.

Já dissemos que as hipergeneralizações caracterizam-se particularmente pela vagueza semântica. Não há precisão a respeito do que se fala, já que o veículo do enunciado possui excessiva amplitude conceitual, o que produz no conceito-chave uma espécie de dispersão e esvaziamento semântico. Termina, assim, por esvaziá-lo de significado relevante e útil para quem o estuda.

As hipergeneralizações terminam, também, por reforçar a ideia de que organizações (e, consequentemente, teorias administrativas e administradores) são questões humanas de todos os tempos e lugares sociais. As "Organizações são quaisquer possíveis coletividades humanas", ou seja, são atividades coletivas humanas ocorridas em qualquer lugar e desde sempre. Falta-lhes, portanto, especificidade e historicidade. Sendo fenômenos de todas as circunstâncias, terminam sendo uma experiência indissociável da ação humana qualquer que seja ela. Ou seja, há uma tendência nos manuais didáticos estudados a descontextualizar historicamente o fenômeno organização, deixando de produzir sobre ele conhecimento especializado para futuros administradores.

Tentando a esta altura sermos um pouco propositivos, entendemos que a única forma de aumentar a precisão semântica dos veículos usados nos conceitos-chave sobre o tópico analisado é estabelecermos uma revisão dos critérios para a criação de um novo paradigma $P^{\prime}$, estabelecido a partir de uma categoria menos abrangente do que "quaisquer possíveis coletividades humanas".

Neste sentido, entendemos que $P^{\prime}$ deve surgir numa perspectiva de entendimento das organizações como um fenômeno que possua datação e especificidade. Estamos falando de "coletividades humanas específicas que surgiram em certo momento histórico", e não de "coletividades humanas" de todos os lugares e de todas as épocas.

Para chegarmos a $P^{\prime}$, torna-se necessário, pois, situarmos historicamente o surgimento das organizações como um tipo bem específico de "coletividade humana". Nossa sugestão é de que Organizações são arranjos produtivos deliberados, surgidos historicamente como consequência das transformações sociais, filosóficas, religiosas, políticas e tecnológicas que marcaram o período histórico da Revolução Industrial, a reboque:

1) Da difusão de certos princípios filosóficos de inspiração iluminista, em especial o liberalismo;

2) Das Revoluções Francesa e Gloriosa, com consequente fim do absolutismo monárquico na França e na Inglaterra;

3) Da consolidação da classe social burguesa mercantil, cujo modelo de orientação produtiva de base capitalista progrediria à fase chamada pelos historiadores de capitalismo industrial;

4) Dos avanços tecnológicos que propiciaram a maquinofatura;

5) Da consolidação do positivismo como princípio metodológico e epistemológico das ciências; entre outros movimentos ocorridos basicamente entre os séculos XVI e XIX.

Foi naquele momento histórico que se concretizou o surgimento de um novo modelo produtivo, qual seja o de produção fabril ou industrial que, sob inspiração da concepção organizacional burocrática, estabeleceu novos moldes às relações de trabalho, com relevantes consequências à vida social, consolidando-se, desse modo, como um marco central do início do Estado Moderno (ARRUDA, 1977; PRESTES MOTTA, 2003, p. 3-4).

Embora tal discussão não seja pacífica, defendemos aqui que é efetivamentecom a indústria, a nova organização da produção e do trabalho, que surge a Administração, pretensamente a nova ciência destinada a entender e aprimorar os mais recentes processos produtivos na fábrica,espaço do novo modelo de trabalho e 
produção da modernidade. Neste sentido, falar em Administração é falar nas organizações modernas. Então, nossa proposta é que asorganizações devem ser compreendidas como um arquétipo de produção coletiva que:

1) Surge em um determinado momento histórico, legitimado por um conjunto datado de concepções de ordem filosófica, social, religiosa, política e tecnológica;

2) Desenvolve-se prioritariamente sob certo modelo econômico com base na posse e acumulação de capital;

3) Funciona a partir de certos princípios operativos, especialmente a racionalidade instrumental, o modelo organizacional burocrático e a lógica de mercado;

4) Desdobra-se, no percurso histórico do século $\mathrm{XX}$, da típica indústria fabril aos muitos tipos de organização, denominadas por alguns de pós-industriais, e aqui grosso modo classificadas como do primeiro, segundo e terceiro setores (respectivamente: governamental, privado e não governamental). ${ }^{7}$

Naturalmente, o surgimento histórico das organizações (e da Administração) é ao mesmo tempo o marco a partir do qual as Teorias Administrativas se constituem como área de pesquisas, cujos contornos se definiram inicialmente em torno da fábrica, seu objeto inicial de investigações, e se ampliaram com o tempo à diversidade dos novos arranjos organizacionais próprios, sobretudo, da segunda metade do século XX.

Desse modo, definir as organizações, enquanto fenômeno de estudo da Administração, mesmo que se admita de partida uma definição ampla - o que em geral caracterizaria simplesmente uma necessária e aceitável generalização -, é fazer referência às organizações modernas. É falar de fenômenos produtivos marcados pela sua inscrição na Modernidade, da qual chegam mesmo a ser os seus caracterizadores.

Então, acreditamos que o paradigma $P^{\prime}$, aplicado a enunciados cujo tópico seja Organizações, poderia ser caracterizado a partir de uma categoria semântica denominada: "organizações modernas da produção e do trabalho", cujo conjunto de léxicos integrantes poderia ser exemplificado no quadro 16:

Quadro 16

\section{Conjunto (incompleto) de léxicos integrantes do paradigma $P$ ' "organizações modernas da produção e do trabalho"}

\begin{tabular}{|cl|}
\hline L.0 & Organizações \\
\hline L.1 & Empresas privadas \\
\hline L.2 & Organizações governamentais \\
\hline L.3 & Organizações não governamentais \\
\hline
\end{tabular}

Fonte: Elaborado pelo autor

\footnotetext{
${ }^{7}$ Estamos conscientes de que é preciso considerar os vários critérios classificatórios de tipos de organizações como, por exemplo, quantidade de funcionários, faixa de faturamento, área de atuação, etc. Nesta nossa análise, citamos esta (primeiro, segundo e terceiro setores) apenas para ilustrar a diversificação do fenômeno que se seguiu à fábrica.
} 


\section{Considerações Finais}

Chegamos ao final de nosso exercício analítico. Partimos da demonstração da existência do paradigma $P$, caracterizado a partir de uma categoria semântica denominada "quaisquer possíveis coletividades humanas", e definidor do veículo dos enunciados usados como conceitos-chave sobre o tópico Organização, nos manuais de introdução às teorias administrativas, usados nos cursos de Administração das maiores e mais importantes IES por todo o Brasil.

Com base em tal verificação, denominamos tais conceitos-chave de hipergeneralizações, em função da vagueza semântica dos respectivos enunciados, particularmente quanto ao seu veículo, confrontado com o paradigma $P$. Em seguida, como sugestão para o aumento da precisão semântica daqueles conceitos-chave, propomos a inclusão de historicidade e especificidade ao paradigma, através da consideração do contexto que deu origem às organizações modernas, e chegamos à proposta do paradigma $P^{\prime}$.

Neste momento, portanto, caberiam algumas questões para a nossa reflexão, enquanto professores, pesquisadores e autores da área. Talvez a mais básica e inquietante seja: quais as implicações educacionais e profissionais produzidas pelo amplo uso de um conceito-chave - definido nestes termos: "organizações são quaisquer possíveis coletividades humanas" - na formação básica de centenas de milhares de alunos nos cursos de Administração das IES por todo o Brasil?

Afinal, o que se pode esperar de uma área de formação profissional (e campo de pesquisas?) que estuda e se aplica a "quaisquer possíveis coletividades humanas"? Não é de se estranhar que alguns autores da área se rendam simplesmente à impossibilidade de conceituação. Outros buscam tal significado no senso comum apresentado pelos dicionários. Não raro, outros ainda chegam mesmo a propor classificações da Administração como arte, ciência, filosofia, técnica, prática ou modo de vida. E, neste caso, ficamos a pensar: para cada uma destas concepções de Administração, qual seria o conceito correspondente de organização?

É evidente que a proposta de $P^{\prime}$ não traz novidades quanto aos seus léxicos integrantes (quadro 16). Isso porque ele remete tão somente à necessidade de ampliarmos a precisão semântica dos conceitos-chave sobre o tópico analisado. Neste sentido, no âmbito da área de Administração, a referência às organizações incluiria as chamadas "organizações modernas da produção e do trabalho": empresas privadas, organizações governamentais e organizações não governamentais (o que já não é pouco).

Por outro lado, a reunião de situações sociais tão diferentes sob uma mesma designação, bem como a aparente desatenção às incompatibilidades entre elas parece confirmar que a racionalidade instrumental, que orienta o comportamento baseado no cálculo utilitário das consequências, como busca pela eficácia no âmbito burocrático-industrial (RAMOS, 1981), há muito se tornou norteadora da vida associada para além das "organizações modernas da produção e do trabalho".

Como afirma Guerreiro Ramos (1981), o marco histórico que situa as organizações como um fenômeno específico caracterizou a sociedade fundamentalmente como centrada no mercado, concepção que produziu no senso comum uma visão extremamente limitada da natureza humana, restringindo suas motivações, anseios e valores à competição e ao interesse pelo ganho puramente econômico. Numa sociedade organizacional, a valorização do indivíduo fica subordinada ao seu papel de detentor de um emprego. "Numa sociedade assim, não ser detentor de um emprego corresponde a não ter valor - e mesmo a não existir" (RAMOS, 1981, p. 101). Pressuposto que, segundo o autor, não havia ocorrido antes do surgimento da sociedade moderna centrada no mercado.

O paradigma $P$, portanto, pode ser entendido como mera consequência desta tendência político-ideológica por uma indistinção “organizações versus não organizações”. E, embora o Paradigma p' seja, talvez, não muito menos arbitrário que o Paradigma $\mathrm{P}$, entendemos que ele seria capaz de oferecer mais precisão 
semântica ao tópico Organizações, de maneira a tornar menos difuso e fluido o fenômeno central da nossa área.

Por fim, salientamos que a vagueza com a qual o tópico "organização" é tratado, nos livros de Introdução à Administração, é problema que transcende em muito uma abordagem meramente acadêmica. Ela produz efeitos éticos relevantes, na medida em que descaracteriza determinadas dimensões da prática social coletiva no mundo das organizações e, desse modo, empobrece a compreensão dos múltiplos aspectos que marcam os fenômenos administrativos.

\section{Referências}

ABRAHAMSON, E. Management fashion. Academy of Management Review, Briarcliff Manor, v. 21, n. 1, p. 254285, Jan. 1996.

ANDRADE, R. O. B. de. Oportunidade de debate sobre os fundamentos, a prática e a evolução do ensino superior de Administração. In: Seminário Teorias da Administração. Recife: Campus-Elsevier, 2009.

ARRUDA, J. J.de A. História moderna e contemporânea. São Paulo: Ática, 1977.

BATEMAN, Thomas S.; SNELL, Scott A. Administração: construindo vantagem competitiva. São Paulo: Atlas, 1998.

BENVENISTE, È. Problemas de linguística geral. São Paulo: Pontes. v. 1. 1991.

BERNARDES, C.Teoria Geral da administração. São Paulo: Atlas, 1993.

CARVALHO, C.Para compreender Saussure. Petrópolis: Vozes, 2005.

CHIAVENATO, Idalberto. Administração de empresas: uma abordagem contigencial. São Paulo: McGraw Hill do Brasil, 1982.

FISCHER, T. M. D. Administração Pública como área de conhecimento e ensino: a trajetória brasileira. Revista de Administração de Empresas, v. 24, n. 4, p. 278-288, out./dez. 1984.

. A formação do administrador brasileiro na década de 90: crise, oportunidade e inovações nas propostas de ensino. Rev. Adm. Pública, v. 27, n. 4, p. 11-20, out./dez. 1993.

GUIA DO ESTUDANTE. Melhores do guia do estudante em 2007. Disponível em: http://guiadoestudante.abril.com.br/premio/sobre/conteudo_400913.shtml. Acesso em: 01 dez. 2008.

_. Brasil possui mais de 5,9 milhões de universitários. Disponível em:

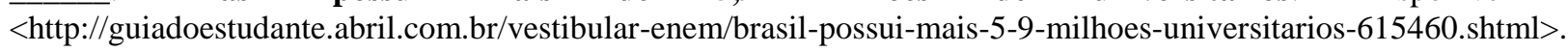
Acesso em: 08 ago. 2011.

INEP. Sinopses Estatísticas da Educação Superior - Graduação. Disponível em: <http://www.inep.gov.br/superior/censosuperior/sinopse/>. Acesso em: 01 dez. 2008.

Sinopses Estatísticas da Educação Superior - Graduação 2009. Disponível em:

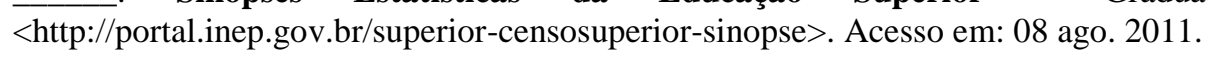

KWASNICKA, E. L. Introdução à Administração. São Paulo: Atlas, 1995.

LACOMBE, F.; HEILBORN, G. Administração: princípios e tendências. São Paulo: Saraiva, 2008. 
MATITZ, Q. R. S.; VIZEU, F. Construção e uso de conceitos em estudos organizacionais: por uma perspectiva social e histórica. Rev. Adm. Pública, v. 46, n. 2, p. 577-598, mar/abr. 2012 . Disponível em: <http://www.scielo.br/scielo.php?pid=S0034-76122012000200011\&script=sci_arttext $>$.

MAXIMIANO, A. C. A. Teoria geral da administração: da revolução urbana à revolução digital. 4. ed. São Paulo: Atlas, 2004.

Teoria geral da administração: da revolução urbana à revolução digital. 5. ed. São Paulo: Atlas, 2005.

Introdução à administração. 7. ed. São Paulo: Atlas, 2007.

MICKLETHWAIT, J.; WOOLDRIDGE, A. Os bruxos da administração: como entender a babel dos gurus empresariais. Rio de Janeiro: Campus, 1998.

MOTTA, F. C. P.; VASCONCELOS, I. F. G. Teoria Geral da Administração. São Paulo: Thomson, 2003.

MOURA, G. L. Ressignificações linguístico-pragmáticas na literatura de formação profissional sobre teoria organizacional: indexando fragilidades (Tese de Doutorado), 2009. Programa de Pós-Graduação em Letras, Universidade Federal de Pernambuco, Recife, 2009.

Uso de metáforas nos manuais de introdução à Administração: instrumentalismos ou desorientação? Recife: Ed. Universitária da UFPE, 2010.

Abusos Metafóricos em Manuais de Introdução à Administração. In: III Encontro de Ensino e Pesquisa em Administração e Contabilidade/EnEPQ, 2011, João Pessoa. III EnEPQ. Anais... Rio de Janeiro: ANPAD, 2011.

NICOLINI, A. Qual será o futuro das fábricas de administradores? In: XXV ANANPAD - Encontro da Associação Nacional dos cursos de Pós-graduação em Administração - ANPAD, 2001. Campinas - SP, 16-19/9/2001. Anais... Rio de Janeiro: ANPAD, 2001 - CD-ROM.

Qual será o futuro das fábricas de administradores? RAE - Revista de Administração de Empresas, v. 43, n. 2, p. 44-54, abr/jun. 2003.

PIETROFORTE, A. V. A língua como objeto da Lingüística. In: FIORIN, José Luiz (org.) Introdução à Lingüística: I. Objetos teóricos. São Paulo: Contexto, 2003.

RAMOS, A. G. A nova ciência das organizações: uma reconceitualização da riqueza das nações. São Paulo: FGV, 1981.

ROBBINS, S. P. Administração: mudanças e perspectivas. São Paulo: Saraiva, 2005.

SAUSSURE, F. Curso de linguística geral. São Paulo: Cultrix, 1969.

STONER, J. A. F.; FREEMAN, R. E. Administração. 5. ed. Rio de Janeiro: Prentice-Hall, 1999.

TAKAHASHI, F. Campeão em número de alunos, administração tem mais estudantes que toda a área de saúde. Disponível

em: <http://www.administradores.com.br/noticias/campeao_em_numero_de_alunos_administracao_tem_mais_estudantes_q ue_toda_a_area_de_saude/8000/>. Acesso em: 14 jul. 2009.

UNIVERSIA. Cresce o interesse dos estudantes pelos cursos de administração de empresas. Disponível em: <http://www.universia.com.br/html/noticia/noticia_clipping_cebj.html>. Acesso em: 14 jul. 2009.

VERGARA, S. C.; CARVALHO JR., D. S. Nacionalidade dos autores referenciados na literatura brasileira sobre organizações. In: XIX ENANPAD - Encontro da Associação Nacional de Pesquisa e Pós-graduação em Administração, 1995, João Pessoa. Anais... João Pessoa: Anpad, 1995. 
; PINTO, M. C. S. Nacionalidade das referências teóricas em análise organizacional: um estudo das nacionalidades dos autores referenciados na literatura brasileira. In: I ENEO - ENCONTRO DE ESTUDOS ORGANIZACIONAIS, 2000, Curitiba. Anais... Curitiba: Anpad, 2000.

Referências teóricas em análise organizacional: um estudo das nacionalidades dos autores referenciados na literatura brasileira. RAC - Revista de Administração Contemporânea, v. 5, n. edição especial, p. 103-121, 2001.

WOOD JR, T.; PAULA, A. P. P. A cultura especializada do management. Organizações \& Sociedade, Salvador, v. 13, n. 38, p. 91-105, jul./set. 2006 .

ZUGMAN, Salmo. Erros cognitivos comuns. Disponível http://www.ictc.com.br/arquivos/erros_cognitivos_comuns.pdf . Acesso em: 08 ago. 2011. 